\title{
High Frequency of Colonization and Absence of Identifiable Risk Factors for Methicillin-resistant Staphylococcus aureus (MRSA) in Intensive Care Units in Brazil
}

Gustavo P. Korn, Marinês D. V. Martino, Igor M. Mimica, Lycia J. Mimica, Paulo A. Chiavone and Luiz R. de S. Musolino
Medical School of Santa Casa de São Paulo, Department of Microbiology and Immunology of Medical School of Santa Casa de São Paulo, Service of Intensive Therapy of Santa Casa de São Paulo, Brazil

Colonization of hospitalized patients with methicillin-resistant Staphylococcus aureus (MRSA) is of increasing concern. To evaluate this problem in Intensive Care Units (ICUs) in Brazil, we studied 100 patients admitted to two ICUs from April to June, 1997. Of the 100 patients, 70 were male, 53 were age 60 years or older, 55 were previously hospitalized, 78 were transferred to the ICU from other hospital units, 49 had received antibiotic therapy, and 66 had undergone recent surgery. Nasal and axillary swab cultures were obtained on admission and every 48 hours thereafter until discharge. MRSA were identified by plating any cultured S. aureus on Mueller-Hinton agar containing $6 \mu \mathrm{g} / \mathrm{ml}$ of oxacillin. At the time of admission, $46(46 \%)$ of the patients were colonized with MRSA. No associated risk factors for acquiring MRSA (age, previous hospitalization, prior surgery) could be identified. Of the 54 patients negative for MRSA on admission, 28 (52\%) became colonized while in the ICU. Sixteen $(22 \%)$ of the 74 colonized patients (colonized either on admission or during ICU stay) had associated respiratory or urinary tract infections due to MRSA, and $9(56 \%)$ died. No correlation with special risk factors (invasive procedures, antibiotic use, age, chronic disease) was identified. MRSA occurred frequently, but there was minimal evidence of associated risk factors. Thus, control of MRSA cannot be accomplished by targeting special factors alone, but requires attention to preventing microbial spread in all areas. Of special concern is the high frequency of acquiring the organism in the ICU (52\%). Education concerning the importance of hand washing, environmental surface cleaning, and barrier protection from infected patients is needed.

Key Words: Staphylococcus aureus, methicillin resistance, hospital infections.

The emergence of multiresistant microorganisms is an increasing problem that requeires continuos and, often expensive, precautions to control the associated nosocomial infections. A multiresistant strain has been defined as one resistant to three groups of drugs [1].

Received on 10 May 2000; revised 10 September 2000.

Address for correspondence: Dr. Gustavo P. Korn. R. Dr. Chibata Miyakoshi, 300 Ap. 111-B, Paraíso do Morumbi. Zip Code: 05750-170. São Paulo - SP, Brazil. Phone: (55 11) 91893485. Fax : (11)3758-2869. E-mail: guga.korn@uol.com.br

The Brazilian Journal of Infectious Diseases 2001;5(1):1-7 (C) 2001 by The Brazilian Journal of Infectious Diseases and Contexto Publishing. All rights reserved. $1413-8670$
Following the introduction of penicillin, there were reports as early as 1945 [2], strains of $S$. aureus were unaffected by penicillin by their production of penicillinase or betalactamase. Initially, they were recorded rarely but they soon became reported worldwide. In spite of the development of semisynthetic penicillins, resistant to the betalactamase activity, other strains appeared that were resistant to methicillin. Synthesis of other penicillins, such as oxacillin, cloxacillin and dicloxacillin, did not delay the emerging multi-resistant organisms [3].

Methicillin-resistant S. aureus (MRSA) emerged as a nosocomial pathogen in the early 1960s [4] when outbreaks of infection were reported in British hospitals 
[5] and in other European countries including Switzerland, Denmark and France [6, 7]. Up to 1976, only two outbreaks [8] were reported in the United States. After 1976, according to National Nosocomial Infections Surveillance System (NNISS) data, strains of $S$. aureus to oxacillin increased from $2.4 \%$ in 1976 , to $29 \%$ in 1991 [9]. Strains of MRSA resistant to methicillin, as well as strains resistant to newer penicillins, remained sensitive to glycopeptide antibiotics such as vancomycin and teicoplanin.

Two basic mechanisms are responsible for the resistance of $S$. aureus to the betalactamic antimicrobials: betalactamase production that destroys these agents; and the alteration of proteins located in the cellular wall of the bacteria, called penicillin binding proteins (PBPs) [10]. All MRSA strains produce altered PBP (PBP2 $\alpha$ or 2') $[11,12]$. This protein is coded by a chromosomal gene denominated mec $A$ [13]. Methicillin resistant $S$. aureus (intrinsic resistance) strains carry the mec A gene and PBP 2' $[14,15]$.

Introduction of MRSA into a health care setting may occur as a result of an infected or colonized patient being admitted, or by the presence of health care professionals colonized with the organism [5]. The main mechanism of MRSA transmission within the hospital is via the hands of health professionals who become colonized by direct contact with patients or contaminated patient materials [11]. Transmission is possible this way because MRSA can survive on the hands for hours [16].

Environmental surfaces also can be a source for MRSA transmission, although this hypothesis is controversial [17. Before the infection is established, patients go through phases that include strain acquisition, followed by varying periods of time to achieve colonization of contaminated mucosa or skin [18].

Risk factors for colonization or infection have been identified. They include advanced age, masculine sex, previous hospitalization, length of hospital stay, admission to a burn unit or intensive care unit (ICU), chronic disease, previous antibiotic therapy, exposure to a colonized or infected patient, exposure to burn wounds or surgical wounds, and undergoing invasive procedures $[4,19]$.
Surveillance cultures can be collected from several anatomical sites including wounds, nostrils, perineum, anal area, feces, and tracheostomy secretions. The process of selecting patients for inclusion in this kind of study is controversial. Some authors recommend starting the study at the time of patient admission and then culturing sequentially during the hospital stay. In spite of logistical difficulties and high cost [20], some authors recommend tracking the spread of the infection from the sentinel case where the infection was detected. This approach is not necessary when the epidemic occurs in a closed unit, such as an ICU [21].

The largest reservoirs of organisms are found in the nostrils of colonized patients. Systematically administere antibiotics remain in low levels in this tissue, allowing for persistence of the microbe.

In Brazil, methicillin is not used. Organisms referred to as MRSA are actually oxacillin resistant Staphylococcus aureus (ORSA). However, as methicillin and oxacillin are similar antibiotics, MRSA is the usually accepted designation. As infections caused by these strains have become more frequent, especially in ICUs [22], establishing the epidemiology of these microorganisms in our hospital environments is of great interest.

The objectives of this study were to evaluate the frequency of patient colonization and /or infection by MRSA at the time of admission to an ICU to identify patients that acquired MRSA during their hospital stay, to describe diseases related to colonization by MRSA, and to determine risk factors (previous admission and/or transfer from another hospital site, advanced age, masculine sex, chronic disease, previous antibiotic therapy, surgery, invasive procedures) for colonization and/ or infection by MRSA.

\section{Materials and Methods}

During the 3 month period of April through June, 1997,100 patients admitted to the adult ICU of general hospitals were evaluated. Axillary and nasal swabs were collected from each patient on admission day, and 
Table 1. Distribution of patients by risk factors and according to whether or not they acquired MRSA while in the ICU

\begin{tabular}{|c|c|c|c|c|c|c|c|}
\hline \multirow[b]{2}{*}{ Risk Factor } & \multicolumn{3}{|c|}{$\begin{array}{l}\text { Acquired MRSA } \\
\qquad(n=28)\end{array}$} & \multicolumn{3}{|c|}{$\begin{array}{l}\text { Did not acquire MRSA } \\
\qquad(n=26)\end{array}$} & \multirow{2}{*}{$\begin{array}{c}\begin{array}{c}\text { No. and percentage of risk } \\
\text { factors for MRSA }\end{array} \\
+ \text { MRSA/at risk }(\%)\end{array}$} \\
\hline & $\begin{array}{l}\text { Yes } \\
(\%)^{*}\end{array}$ & No & $\begin{array}{l}\text { data } \\
\text { missing }\end{array}$ & $\begin{array}{l}\text { Yes } \\
(\%)^{* *}\end{array}$ & No & $\begin{array}{l}\text { data } \\
\text { missing }\end{array}$ & \\
\hline $\begin{array}{l}\text { Prior surgery } \\
(\mathrm{n}=36)\end{array}$ & $\begin{array}{c}17 \\
(61 \%)\end{array}$ & 7 & 4 & $\begin{array}{c}19 \\
(73 \%)\end{array}$ & 3 & 4 & $\begin{array}{l}17 / 36 \\
(47 \%)\end{array}$ \\
\hline Prior hospitalization & $\begin{array}{c}16 \\
(57 \%)\end{array}$ & 12 & - & $\begin{array}{c}14 \\
(54 \%)\end{array}$ & 12 & - & $\begin{array}{l}16 / 30 \\
(53 \%)\end{array}$ \\
\hline $\begin{array}{l}\text { Transfer from another } \\
\text { unit in the hospital }\end{array}$ & $\begin{array}{c}24 \\
(86 \%)\end{array}$ & 4 & - & $\begin{array}{c}19 \\
(73 \%)\end{array}$ & 7 & - & $\begin{array}{l}24 / 43 \\
(56 \%)\end{array}$ \\
\hline Age 60 or older & $\begin{array}{c}20 \\
(71 \%)\end{array}$ & 8 & - & $\begin{array}{c}10 \\
(39 \%)\end{array}$ & 16 & - & $\begin{array}{l}20 / 30 \\
(67 \%)\end{array}$ \\
\hline Male & $\begin{array}{c}22 \\
(78 \%)\end{array}$ & 6 & - & $\begin{array}{c}17 \\
(65 \%)\end{array}$ & 9 & - & $\begin{array}{l}22 / 39 \\
(56 \%)\end{array}$ \\
\hline Chronic disease & $\begin{array}{c}5 \\
(18 \%)\end{array}$ & 19 & 4 & $\begin{array}{c}3 \\
(12 \%)\end{array}$ & 19 & 4 & $\begin{array}{l}5 / 8 \\
(63 \%)\end{array}$ \\
\hline Previous antibiotics & $\begin{array}{c}13 \\
(46 \%)\end{array}$ & 9 & 6 & $\begin{array}{c}10 \\
(39 \%)\end{array}$ & 12 & 4 & $\begin{array}{l}13 / 23 \\
(57 \%)\end{array}$ \\
\hline Invasive procedure & $\begin{array}{c}14 \\
(50 \%)\end{array}$ & 10 & 4 & $\begin{array}{c}10 \\
(39 \%)\end{array}$ & 12 & 4 & $\begin{array}{l}14 / 24 \\
(58 \%)\end{array}$ \\
\hline
\end{tabular}

* percentage of the total who acquired MRSA.

** percentage of total who did not acquire MRSA.

Table 2. Distribution of colonized patients with or without infection according to risk factors

\begin{tabular}{lrccccc}
\hline Colonized $(\mathbf{n = 7 4 )}$ & \multicolumn{3}{c}{ With infection $(\mathbf{n = 1 6 )}$} & \multicolumn{3}{c}{ Without infection $(\mathbf{n = 5 8})$} \\
\hline Risk factor & Yes & No & data missing & Yes & No & data missing \\
Prior surgery & $10(63)$ & 6 & - & $35(60)$ & 20 & 3 \\
Prior hospitalization & $7(44)$ & 9 & - & $31(54)$ & 25 & 2 \\
Transfer from other unit & $14(88)$ & 2 & - & $45(78)$ & 11 & 2 \\
Age 60 years or older & $7(44)$ & 9 & - & $36(62)$ & 22 & - \\
Masculine sex & $12(75)$ & 4 & - & $41(71)$ & 17 & - \\
Chronic disease & $7(44)$ & 9 & - & $10(17)$ & 45 & 3 \\
Prior antibiotics & $10(63)$ & 5 & 1 & $29(50)$ & 23 & 6 \\
Invasive procedure & $9(56)$ & 7 & - & $30(52)$ & 23 & 5 \\
\hline
\end{tabular}


Table 3. Distribution of all patients colonized and not colonized according to the risk factors

\begin{tabular}{|c|c|c|c|c|c|c|}
\hline \multirow[b]{2}{*}{ Risk factor } & \multicolumn{3}{|c|}{$\begin{array}{l}\text { Colonized with MRSA } \\
\qquad(\mathrm{n}=74)\end{array}$} & \multicolumn{3}{|c|}{$\begin{array}{l}\text { Not colonized } \\
\quad(n=26)\end{array}$} \\
\hline & Yes & No & data missing & Yes & No & data missing \\
\hline Prior surgery & $45(61)$ & 26 & 3 & $21(81)$ & 4 & 1 \\
\hline Prior hospitalization & $38(51)$ & 34 & 2 & $14(54)$ & 12 & - \\
\hline Transfer from other unit & $59(80)$ & 13 & 2 & $19(73)$ & 7 & - \\
\hline Age 60 years or older & $43(78)$ & 31 & - & $10(39)$ & 16 & - \\
\hline Masculine sex & $53(73)$ & 21 & - & $17(65)$ & 9 & - \\
\hline Chronic disease & $17(23)$ & 54 & 3 & $03(12)$ & 22 & 1 \\
\hline Prior antibiotics & $39(53)$ & 28 & 7 & $10(39)$ & 15 & 1 \\
\hline Invasive procedure & $39(53)$ & 30 & 5 & $10(39)$ & 15 & 1 \\
\hline
\end{tabular}

successively at every 48 hours during the hospital stay, plus an additional sample at the time of transfer to another unit.

Swabs were done each day between 7:00 and 9:00, 12:00 and 14:00, 16:00 and 18:00 hours to ensure that the first collection was performed as close to each patient's time of admission to the unit as possible. All the swabs were plated immediately on Chapman medium and incubated for $16 \mathrm{~h}$ to $18 \mathrm{~h}$ at $35^{\circ} \mathrm{C}$ to $37^{\circ} \mathrm{C}$. At the end of that period, and when the presence of Staphylococcus aureus was confirmed, a sample was placed in a broth culture and maintained until a bacterial concentration of $10^{8}$ colony forming units per $\mathrm{ml}(\mathrm{CFU} / \mathrm{ml})$ was achieved. Screening for MRSA was done as follows: a sample from a $S$. aureus culture was inoculated, with the aid of a swab, onto a plate of Mueller-Hinton agar supplemented with oxacillin at a concentration of $6 \mu \mathrm{g} / \mathrm{ml}$, and containing $4 \%$ of $\mathrm{NaCl}$ (Probac of Brazil). An organism was considered resistant if the strain grew after incubating the plate for $24 \mathrm{~h}$ at $35^{\circ} \mathrm{C}$ to $37^{\circ} \mathrm{C}$.

To evaluate the contribution of risk factors in colonization by MRSA, the following demographic data were collected on each patient; previous surgery, previous hospitalization, admission to another hospital ward and then transfer to the ICU, advanced age (60 years of age or older), gender, the presence of chronic disease, and previous antibiotic therapy.
The data were processed in Epi-Info using the quiSquare for analysis of statistical significance, considering $\propto=0.05 \%$.

\section{Results}

$\underline{\text { Demographic data }}$

The 100 adults admitted to the ICU included 70 males and 30 females. They had a mean age of 57 years distributed as follows: 6 under age 21, 12 age 21-40, 29 age 41-60 and 53 over 60 years of age ( 3 of those over 60 were in the age range of 81 to 90 years). A total of 880 swab cultures were obtained, one from the axillary and one from the nasal region, at 440 different time points. The number of swab cultures collected from each patient was 1 to 5 from 82, 6 to 10 from 11, 11 to 15 from 3, and more than 15 cultures from 4 patients. A chronic disease was recorded in 20 patients. These included hypertension, chronic airway disease and diabetes mellitus. Forty nine had received antibiotic therapy within the past 6 months. Fifty-five patients had had a previous hospitalization, and 78 were transferred to the ICU from another unit of the hospital. Sixtysix patients had undergone previous surgery. These demographic features were used to evaluate risk factors for acquiring MRSA. 
Patients with MRSA identified or not at the time of admission to the ICU

Of the 100 patients, 46 had MRSA isolated at the time of admission; none of these had evidence of ongoing infection due to the organism. Of those colonized, 36/78 (46\%) arrived at the ICU from another area of the hospital; 26/66 (39\%) had previous surgery; 22/55 (40\%) had a previous hospital admission; $25 / 49(51 \%)$ had received antibiotics previously; 23/53 (43\%) were older than 60 years; $31 / 70$ (44\%) were male; and 12/20 (60\%) had a chronic disease. None of these potential risks for acquiring MRSA indicated a statistically significant factor for having the organism. Of particular note is that 9 patients, from whom MRSA was isolated at the time of admission to the ICU (20\%), had no history of previous hospitalization, nor were they transferred from another unit in the hospital.

\section{Patients who acquired MRSA were in the ICU}

Twenty eight of the 54 patients not colonized with MRSA at the time of admission to the ICU acquired the organism while being cared for in the unit (52\%). By examining risk factors for acquiring the organism while in the ICU, the following were found: over age 60 years, 20/30 (66\%) became colonized; chronic disease, 5/8 (63\%); invasive procedures 14/24 (58\%); previous antibiotics 14/24 (58\%); undergoing prior surgery $17 / 36(47 \%)$; male gender $(56 \%)$; transferred from another unit 24/43 (56\%); and previous hospitalization 16/30 (53\%). Thus, for those over 60 and with chronic disease, there is a slightly greater risk of acquiring MRSA while in the ICU, although this did not reach statistical significance. Table 1 presents this data in tabular form.

\section{$\underline{\text { Risk factors for infection in those colonized by MRSA }}$}

Table 2 shows the distribution according to risk factors of the 16 patients who developed infections after isolation of MRSA. The most frequent risk factor was the presence of an underlying chronic disease 7/
$17(41 \%)$. Other risk factors ranged between $16 \%$ and $24 \%$. The types of infections manifest among those infected included respiratory or urinary tract infections.

Nine of the 16 patients infected with MRSA (56\%) died from their infections, thus confirming the high mortality associated with this infection.

\section{$\underline{\text { Overall summary of risk factors for MRSA }}$}

Table 3 includes the data on all of the 74/100 patients $(74 \%)$ who had MRSA at the time of admission to the ICU, or acquired it in the unit. Of those with previous surgery, 45/66 (68\%) were colonized; 59/78 (76\%) of those transferred from other units, $38 / 52(73 \%)$ with previous hospitalization, $43 / 53(81 \%)$ were over the age of 60 years; $39 / 49(80 \%)$ underwent invasive procedures; $39 / 49$ (80\%) had received prior antibiotics; and 53/70 (76\%) males acquired the MRSA organism. These data indicate that no special group was protected or more susceptible to acquiring the organism. On the other hand, the data indicated that acquisition of MRSA is a very common problem and is associated with the occurrence of infections resulting in a high mortality rate.

\section{Discussion}

S. aureus has been an important pathogen for many decades. Due to the increasing number of infections caused by strains of methicillin-resistant $S$. aureus (MRSA), the therapies for these microorganisms have become progressively more difficult [23].

The data in this work led to a series of reflections regarding MRSA. Due to the high colonization level present at the time of admission to the ICU (46\%), or during treatment in the ICU (52\% of those that did not have MRSA on admission), and knowing that the presence of the bacteria in those patients can be a source of contamination in this type of unit, great emphasis must be placed on instituting control measures to prevent its spread. 
In accordance with the current norms of the CDC [24], patient carriers of multi-resistant bacteria are targeted to receive "Contact Precautions". These include the need for an isolated room or, when this is not possible, the patients can share a room with other carriers of the same bacteria (cohorts).

Many studies have shown advantages in using antiseptics in the hand washes [27,28], since this is the most important route for MRSA transmission. The use of gloves for all the people that enter the room is recommended, since these patients are generally colonized at multiple anatomic sites and the patient's environment remains massively contaminated [25]. In contrast, the use of a mask and gown has not been shown to have documented value [26].

General measures of control include: 1) identification of patients who are colonized or infected with MRSA at the time of admission and during the period of hospitalization; 2) careful attention to the precautions described above to avoid the dissemination of the organism to the health care staff and visitors.

The $22 \%$ of colonized patients that developed infection is slightly lower than the $30 \%$ to $60 \%$ described in the literature $[29,30]$. The antibiotics needed to treat them are expensive, and include drugs such as vancomycin and teicoplanin. There is further concern regarding observations of increasing resistance of enterococcus to vancomycin in some countries, and for the possibility that this type of resistance could be transmitted to $S$. aureus. Recent reports indicate isolation of strains of $S$. aureus with intermediary sensitivity to vancomycin (VISA) [31, 32].

In this study, no significant factors associated with colonization and/or infection were identified. One interesting finding was that $20 \%$ of the patients colonized at admission did not have a previous admission or transfer from another unit, even though these strains are typically from the hospital environment. In another study in the USA, 8 cases of MRSA were considered to be from the community [33].

The increasing frequency of MRSA strains remains a problem which must be solved quickly.

\section{Acknowledgement}

The authors thank Claudia Masella Villoso, Maria Angela Gonçalves Paschoal, Neide Marcela Lucínio, Lúcia Aparecida Gonçalves, Carmem Lúcia Arneiro, Mônica Agostini Silva, Mirene Jeter Lavander and Isabel Rosa Evangelista for nursing assistance.

\section{References}

1. Breiman R.F., Tenover F.C., Elliot J.A., Facklam R.R. Emergence of drug-resistant pneumococcal infections in the United States. JAMA 1994;271:1875-6.

2. Spink W.W., FERRIS V. Quantitative action of penicillinresistant strains of staphylococci. Science 1945;102:201.

3. Barber M. Methicillin-resistant staphylococci. J Clin Pathol 1961;1:124-5.

4. ThompsonR.I., Cabezudo I., Wenzel R.P. Epidemiology of nosocomial infections caused by methicillin-resistant Staphylococcus Aureus. Ann Intern Med 1982;97:309-17.

5. Stewart G.P., Holt R.J. Evolution of natural resistance to the new penicillins. Br Med J 1962; 1:309-11.

6. Kayser F.M. Methicillin-resistant staphylococci 1965-75. Lancet 1975;2:650-3.

7. Siboni K., Poulsen L., Digman E. The dominance of methicillin-resistant staphylococci in the country hospital. Danish Med Bull 1968; 15:161-5.

8. Haley R.W., Hightower A.W., Khabbaz R.F., et al. The emergence of methicillin-resistant Staphylococcus aureus infections in United States hospitals. Possible roles of the house staff-patient transfer circuit. 197591. Ann Intern Med 1982;97:297-308.

9. Panillo A.L., Culver D.H., Gaynes R.P., et al. Methicillinresistant Staphylococcus aureus in U. S. hospitals. 1975-91. Infect Control Hosp Epidemiol 1992;13:582-6.

10. Mulligan M.E., Murray-Leisure K.A.M., Ribner B.S., et al. Methicillin-resistant Staphylococcus aureus: The consensus review of microbiology, pathogenesis, and epidemiology with implication goes prevention and management. Am J Med 1993;94:313-28.

11. Hartamn B.J., Tomaz A. Expression of methicillin resistance in heterogeneous strains of Staphylococcus aureus. Antimicrob Agents Chemother 1986;29:85-92.

12. Utsui Y., Yakota T. Role of an altered penicillin-binding protein in methicillin and cephem-resistant Staphylococcus aureus. Antimicrob Agents Chemother 1982;29:85-92.

13. Geordopapadakou N.H., Smith P.A., Bonner D.P. Penicillinbinding proteins in Staphylococcus aureus strains resistant to specific beta-lactam antibiotics. Antimicrob Agents Chemother 1982;22:172-5. 
14. Archer G.L., Pennel E. Detection of methicillin-resistance in staphylococci by using to DNA probe. Antimicrob Agents Chemother 1990;34:1720-4.

15. Gerberding J.L., Mick C., Liu H.H., Chambers H.F. Comparision of conventional susceptibility tests with direct detection of penicillin binding protein $2 \mathrm{a}$ in borderline oxacillin-resistant strains of Staphylococcus aureus. Antimicrob Agents Chemother 1991;35:2574-9.

16. Sabath L. Chemical and physical factors influencing methicillin resistance of Staphylococcus aureus and Staphylococcus epidermidis. J Antimicrob Chemother 1977;3:47-51.

17. Aldrige K.E. Methicillin resistant Staphylococcus aureus: clinical and laboratory features. Infect Control 1985;6:461-5.

18. French G.L., Philips I. Antimicrobial resistance in Hospital Flora and Nosocomial Infections. In: Mayhall C.G. [ed.]. Baltimore, Williams \& Wilkins. Hospital Epidemiology and Infection Control 1996:980-99.

19. Asensio A., Guerrero A., Quereda C., et al. Colonization and infection with methicillin-resistant Staphylococcus aureus: associated factors and eradication. Infec Control Hosp Epidemiol 1996; 17:20-8.

20. Boyce J.M., Laundry M., Deetz T.R., Dupont H.L. Epidemiologic studies of the outbreaks of nosocomial methicillin-resistant Staphylococcus aureus infections. Infect Control 1981;2:110-6.

21. Cutler R.R. Relationship between antibiotic resistance, the production of virulence factors, and virulence in experimental animals in Staphylococcus aureus. J Med Microbilol 1979; 12:55-62.

22. Russell A.D., Hugo M.B., Ayliffe G.A.J. F. methicillinresistant staphylococci. In: Principle and practice of disinfecting and sterilization. London, Blackwell Scientific, 1992. p.264-73.

23. Kluytmans J., Van Belkum A., Verbrugh H. Nasal carriage of Staphylococcus aureus; epidemiology, underlying mechanisms, and associated risks. Clin Microb Rev 1997; 10:505-20.

24. Boyce J.M. MRSA in hospitals and long-term care facilities: microbiology, epidemiology and preventive measures. Infect Hosp Epidemiol 1992;13:725-37.

25. Cookson B., Peters B., Webner M., et al. Staff carriage of epidemic methicillin-resistant Staphylococcus aureus. Resistance to methicillin and aminoglycosides.I:clinical studies. J Infect Dis 1979; 139:273-9.

26. Cohen S.H., Morita M.M., Bradford M.A. Seven-years experience with methicillin-resistant Staphylococcus aureus. Am J Med 1991;(91Suppl 3B):233S-7S.

27. Garner J.S. The hospital infection control practices advisory committee. Guidelines for isolation precautions in hospitals. Infect Control Hosp Epidemiol 1996; $17: 54-80$.
28. Maki D.G., Zilz M.A., Alvarado C.J. Evaluation of the antibacterial efficacy of four agents for handwashing. In: Proceedings and Abstract of the ICAC. $19^{\text {th }}$ ICAC, 1980.

29. Alan I.H., Mulligan M.E. Methicillin-resistant Staphylococcus aureus. Hosp Epidemiol Infect Control 1996;290-306.

30. Cossley K., Landesman B., Zaske D. An outbreak of infections caused by strains of nosocomial Staphylococcus aureus resistant to methicillin and aminoglycosides.II:epidemiologic studies. J Infect Dis 1979; 139:280-7.

31. Staphylococcus aureus with reduced susceptibility to vancomycin - United States, 1997. MMWR Morb Mort Wkly Rep 1997;46:813-5.

32. Update: Staphylococcus aureus with reduced susceptibility to vancomycin - United States, 1997. MMWR Morb Mort Wkly Rep 1997;46:765-6.

33. Flouroy D.J. Methicillin-resistant Staphylococcus aureus at the Vaterans Affairs Medical Center (1986-96). J Okla State Med Assoc 1997;90:228-35. 